\title{
Development of a cutting edge temperature measurement of end mill tool by using infrared radiation technique
}

\author{
M. A. Kiprawi ${ }^{1}$, A. Yassin ${ }^{1}$, A. M. N. A. Kamaruddin ${ }^{1}$, S. T. S. Shazali ${ }^{1}$, \\ M. S. Islam ${ }^{1}$ and M. A. M. Said ${ }^{1}$ \\ ${ }^{1}$ Department of Mechanical and Manufacturing Engineering, Faculty of Engineering, \\ Universiti Malaysia Sarawak, 94300 Kota Samarahan, Sarawak, Malaysia \\ Phone: +6013-8152273; Fax: +6082-583409 \\ *Email: yabdulla@unimas.my
}

\begin{abstract}
This paper describes the development of cutting temperature measurement of end mill tool by using infrared radiation technique approach. Compared to conventional thermocouple technique, infrared radiation technique is an advance method of measuring temperature which featured high accuracy, high response rate, wide range of temperature scale detection and almost compatible with all materials used in the manufacturing industry. We measures the emission of infrared radiation from the source, which is cutting edge of tool by using photocells that contains InAs and InSb photovoltaic detectors. Photocells converts the infrared radiation to a voltage signal and then recorded by oscilloscope followed with a calibration with its corresponding temperature. This paper discussed about the calibration method, cutting experiment setup, the limit of infrared radiation level detected by photocells, signal correction of output signal, and relations of peak signal formation with rotation of end mill tool. The developed pyrometer is also capable to profile the cutting tool's rotation based on the movements of infrared radiation's emission at cutting tool's edge. The conclusion was that the measurement of cutting temperature of high speed machining by using infrared radiation technique is possible. The developed pyrometer are capable to detect temperature changes at a span of $0.01 \mathrm{~ms}$.
\end{abstract}

Keywords: Pyrometer; end milling; infrared radiation; signal processing; cutting temperature.

\section{INTRODUCTION}

A machining process in manufacturing is one of the important process in product fabrication. The fabrication process requires removal of unwanted material from the workpiece to obtain a desired shape with high dimensional accuracy of the parts or products. High speed machining is used to produce a product that requires high surface integrity with excellent dimensional accuracy. Unfortunately, usage of high speed machining will cause high tool wear rate [1]. Tool wear affects the workpiece surface integrity. Main causes of tool wear are poor chip formation mechanism, poor coolant system, wrong cutting tool material for particular workpiece and wrong choice of cutting speed condition during machining. These factors cause multiple deformation of the cutting tool [2]. The friction resistance over the 
time dissipates as thermal energy [3]. Accumulation of thermal energy will increase the cutting temperature. Once the cutting temperature reaches melting point of cutting tool, the cutting edge of tool will start to soften [4]. As a result, prolonged use of cutting tools in high speed machining will cause frequent replacement of cutting tool and resulting in an increase of manufacturing cost. Therefore, determination of the cutting temperature to study the performance of cutting tools at particular cutting speed is crucial. Previous researcher have done extensive studies on the milling temperatures. Sato, Tamura and Tanaka (2011) [5] have studied the temperature and force variation existed during the milling process of titanium alloy Ti-6Al-4V. They compare the differences of the cutting temperature between down milling and up milling. They discovered that cutting temperature gradient is higher in down milling compared to the latter. Ueda, Hosokawa, Oda and Yamada (2001) [6] also found that increasing cutting speed will reduce finished surface temperature, but increasing tool-chip contact temperature. Furthermore, Ueda et al. (2001) [6] and Kiprawi, Yassin, Syed Shazali, Islam, \& Mohd Said (2017) [7] studied the effects of cutting speed and depth of cut on cutting tool temperature of cemented carbide insert. They concluded that the increasing cutting speed and depth of cut will increase the cutting temperature. Cutting speed is the major factor of changes in cutting temperature followed by the depth of cut and feed per tooth [6-9]. Apart from experimental method, there are empirical and analytical models approach to determine the distribution of energy during machining to simulate the machining process [10-12]. There are research on the effects of lubricants in machining process [8, 13-15]. By using a thermocouple as a direct contact temperature measurement tool, they found that the cutting temperature decrease when a lubricant is applied. In the latest research, Di, Dinghua, Baohai, \& Ming (2017) [16] have performed a study on end milling using carbide tool with a difficultto-machine materials, TiAl6V4. They made a comparison between an experimental method by using thermocouple technique at low cutting speed and mathematical model. They found that increasing cutting speed and feed per tooth will increase the temperature at the tool-chip interface. Di et al. (2017) [16] have used a simplified analytical model of the cutting loads and stress-strain zone during cutting process based on research conducted by Ma, Feng, Zhang, Wu, \& Yu (2016) [17]. Ma, Yu, Feng, Wu, \& Zhang, (2015) [18] used a Finite Element Method (FEM) model and showed that initial tensile stress makes the cutting stress distribution within the workpiece become more tensile. This condition is caused by thermal effect from the cutting temperature. Di, Dinghua, Baohai, \& Ming, (2017b) [19] furthered the analytical model research by relating the cutting temperature with flank wear. They postulated that flank wear gives an impact on tool temperature directly, but the growing of flank wear loses its influences on tool temperature. The tool temperature begins to rise at high rate, then becomes steady state, which is temperature rise slowly until reaches peak value. In these latest researches, obtaining a real cutting temperature parameter is important for developing a simulation model. Unfortunately, thermocouple technique have its own limitations when measuring cutting temperature.

Utilizing electromagnetic radiation (e.m.f.) emitted from cutting tool during machining process as a non-contact temperature measurement [6-7, 20-21] is an alternative to the direct contact method. The advantages of non-contact method as a technique of measuring a cutting temperature outweighs the disadvantages of contact method in terms temperature detection range, real-time measurement, non-invasive and durable [22]. The main disadvantage of using thermocouple method is that, it is not applicable to be used on non-conductive cutting tool's material such as ceramics and diamond. Furthermore, 
thermocouple technique measures temperature by averaging thus it is not a true cutting temperature. Based on the previous research, there are less amount of study on cutting temperature of diamond cutting tool. Therefore, development of pyrometer technique to measure a cutting temperature of machining process on a rarer cutting tool material is important for research purpose and machining industry. The measured actual cutting temperature is also beneficial as one of the main tool to establish comparative study with analytical and simulation model in the future.

\section{METHODS AND MATERIALS}

\section{Design of Experiment}

A schematic illustration of the experimental setup was shown in Figure 1 and based on previous research [6-7, 20-21]. A single indexable end milling cutter was used and optical fiber was positioned at an angle of $180^{\circ}$ from the initial contact point of end mill tool on the workpiece. Insert carbide installed in end mill tool holder is made from carbide material coated with titanium carbo-nitiride (TiCN). Chalcogenide optical fiber was used as a medium for infrared radiation to travel easily at desired path. The position of the insert was indicated in Figure 1. The gap distance between insert carbide and optical fiber is $0.5 \mathrm{~mm}$. The rake face of the insert carbide tip radiates infrared waves and received by the optical fiber. Optical fiber emits the received infrared waves to InAs and InSb photocells to produce an analogue signal. The signal produced was amplified by amplifier to obtain a range of the millivolt analogue signal. The cutting temperature was determined by using a ratio between the voltage output of InAs and InSb photocell (Table 4) and using the calibration curve shown in Figure 4 [23]. Practically, the emissivity of insert carbide will change due to oxidation effect [22]. For this research, the effects of emissivity are ignored, as two-colour/bicolor pyrometer are capable to minimize greatly the emissivity issue as long as the detection range of temperature of sensors are majorly overlapping [23-24]. The photocells were placed in a blackbody box to provide a condition almost similar to blackbody radiation. The signal recorded will then processed by using Xviewer, Ngraph and Matlab software.

\section{Experimental Procedure}

The cutting experiment was carried out based on the conditions shown in Table 1. AISI 1095 Carbon Steel was used as a workpiece and insert carbide coated with TiCN was used for cutting tool (Figure 1). During experiments, cutting speed was set to $283 \mathrm{~m} / \mathrm{min}$ and up cutting process was chosen. The workpiece was installed on the dynamometer and cutting forces are measured. Noted that the dynamometer, which contains piezoelectric sensor [43] is not a main component to measure the cutting temperature. It was included in the experimental setup as we intend to proof that the cutting temperature's profile produced by photocells and cutting force's profile produced by dynamometer were related to each other. 
Table 1: Experimental conditions in milling

\begin{tabular}{l|l}
\hline Cutting tool (tool tip) & APKT 1604 PDTR; Insert: TiCN-coated carbide (P10 - \\
& P35); Diameter of insert holder: $20 \mathrm{~mm}$ \\
\hline Cutting speed, $\mathrm{v} /$ Feed, $\mathrm{f}$ & $\mathrm{v}=283 \mathrm{~m} / \mathrm{min} ; \mathrm{f}=0.1 \mathrm{~mm} /$ tooth \\
\hline Depth of Cut & $\mathrm{R}_{\mathrm{d}}=1.0 \mathrm{~mm} ; \mathrm{A}_{\mathrm{d}}=1.0 \mathrm{~mm}$ \\
\hline Cutting fluid & None (Dry cut) \\
\hline Optical fiber: chalcogenide & Core diameter, dc: $340 \pm 10 \mu \mathrm{m}$ \\
glass fiber & Transmission range: $1.5-6 \mu \mathrm{m}$ \\
& Core material: $\mathrm{As}_{2} \mathrm{~S}_{3} ;$ Effective NA: $0.30 \pm 0.03$ \\
& Acceptance angle, $\xi \mathrm{m}: 17.45^{\circ}$ \\
\hline & \multicolumn{2}{|c}{ Condenser: $\mathrm{BaF}_{2}$} \\
\hline
\end{tabular}

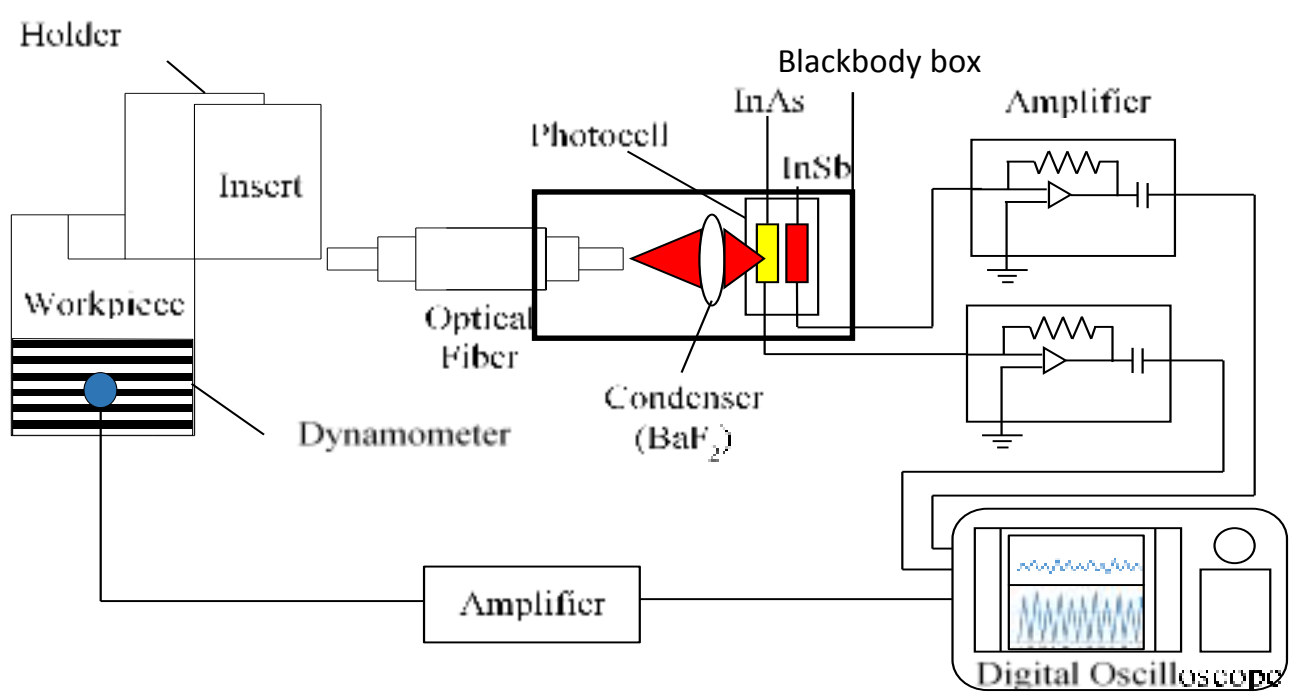

(a) Schematic View

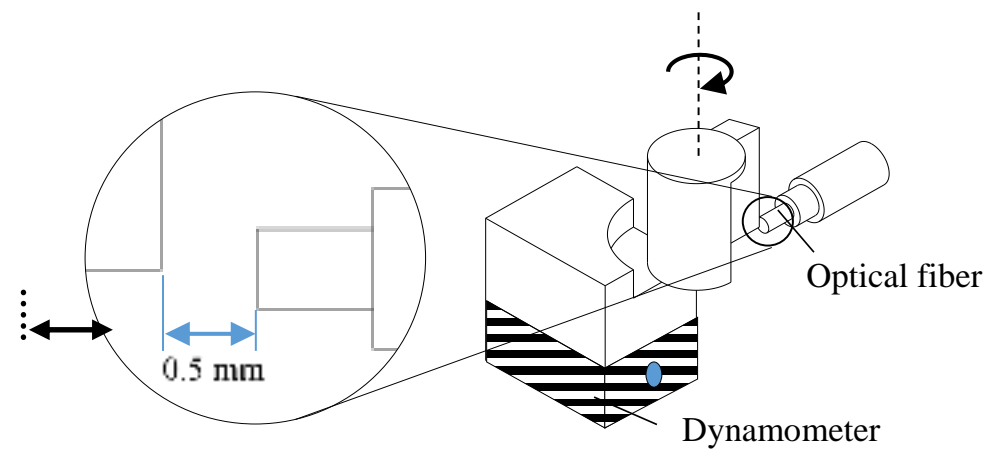

(b) View of optical fiber's position - zoomed in 


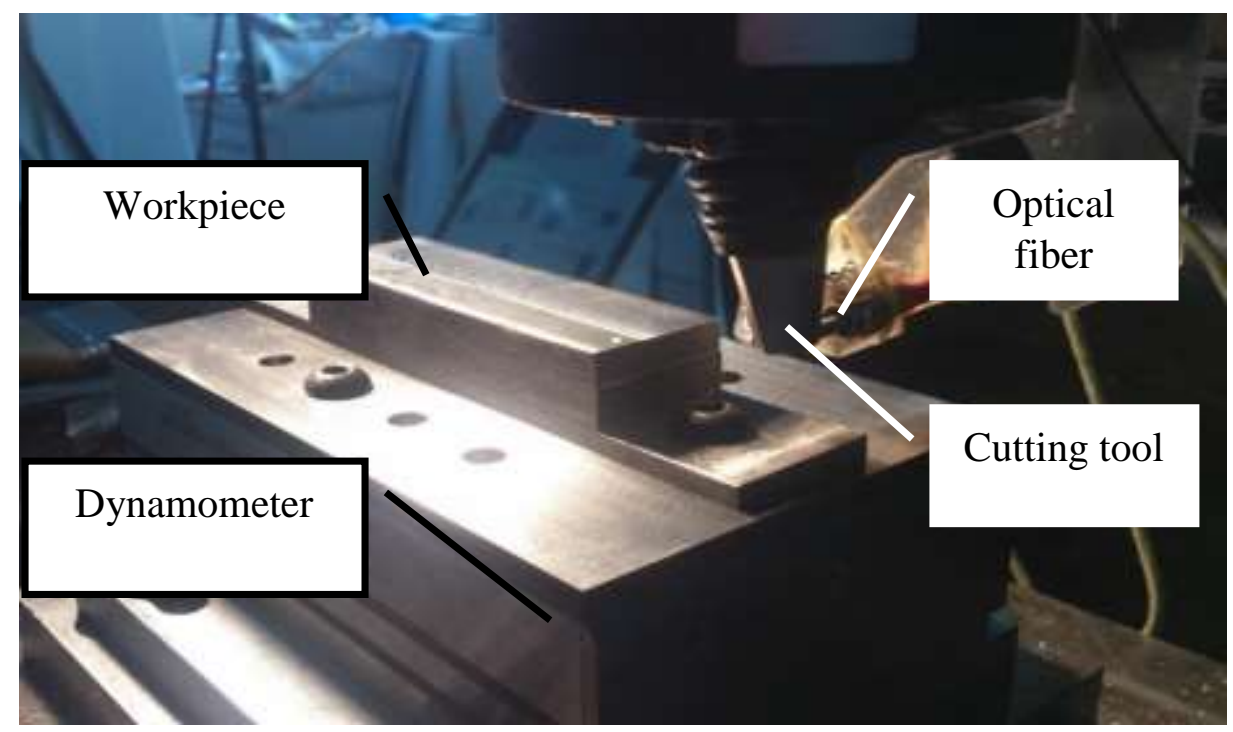

(c) Image of optical fiber pointed at the cutting edge of tool

Figure 1: Experimental setup (a) schematic view; (b) view of optical fiber's position; (c) image of optical fiber pointed at cutting edge of tool.

\section{Pyrometer Calibration Setup}

A calibration for insert carbide coated with TiCN was performed as shown in Figure 2. An insert carbide was heated up until $900^{\circ} \mathrm{C}$ by butane pencil torch. Refractory ceramic fiber or isowool was wrapped around the insert carbide to minimize the heat energy loss to the surroundings. A heated insert carbide emits an infrared radiation that travels through optical fiber and condenser before being accepted by InAs and InSb photocell sensor [25]. Photocell converts the infrared radiation to analogue voltage. Terminals output behind photocell were connected to the amplifier to amplify the signal. High speed digital oscilloscope was connected to the amplifier to measure, record and visualize the signal in graphical form.

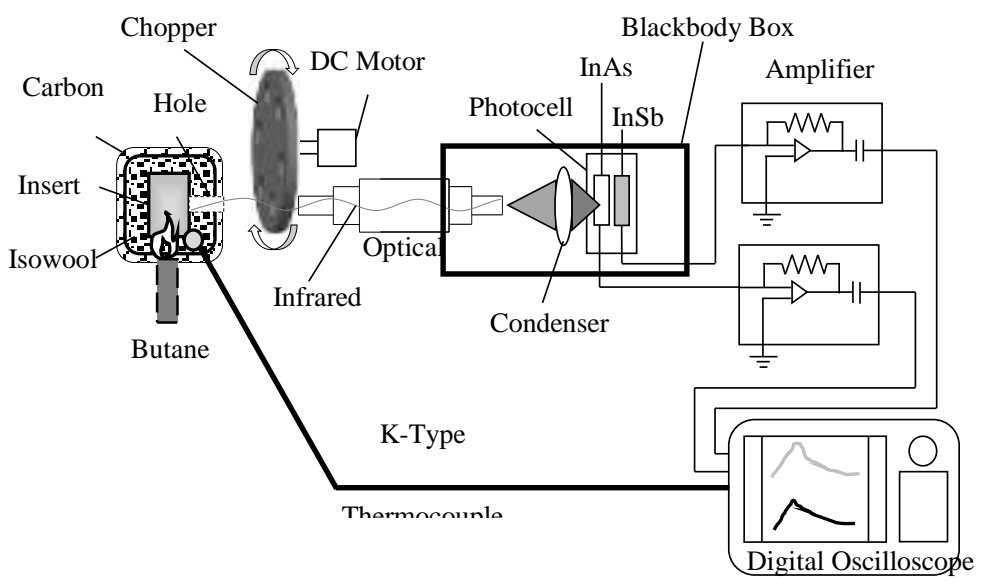

Figure 2: Calibration setup of temperature measurement of insert carbide 


\section{Condenser}

A scattered infrared radiation wave means a lot of radiation energy lost to the surroundings. An energy lost will gives a less dense infrared radiation. This situation will further impact on the infrared detector to detect infrared radiation at low temperature surface. For this pyrometer, BaF2 lens and its specifications in Table 2 was used to condense the infrared rays radiated from the optical fiber before they are accepted by the InAs and InSb infrared detector [25].

Table 2: Specifications of $\mathrm{BaF} 2$ condenser.

\begin{tabular}{ll} 
Diameter, $\mathrm{d}_{\mathrm{L}}$ & $12.7 \mathrm{~mm}$ \\
Focal length, $\mathrm{f}$ & $25 \mathrm{~mm}+/-2 \%$ \\
Transmission range, $\mu \mathrm{m}$ & $0.15-12$ \\
Refractive index & $@ 0.265 \mu \mathrm{m}, \mathrm{n}=1.51217$; @ $10.3 \mu \mathrm{m}, \mathrm{n}=1.39636$ \\
Density, $\mathrm{g} / \mathrm{cm}^{3}$ & 4.89 \\
Melting point, ${ }^{\circ} \mathrm{C}$ & 1386 \\
\hline
\end{tabular}

\section{Specifications of InAs and InSb photocells}

For this pyrometer development, Indium Arsenide (InAs) and Indium Antimonide (InSb) were used as infrared detectors and its specifications were shown in Table 3. Both of them are photovoltaic detectors. InAs and InSb sensors were installed in a sandwich configuration in order to ensure a single unique infrared radiation wave were able to pass through both sensor. InAs and InSb photocells are high speed response infrared sensor. The temperature detection range for each photocells were determined using Planck's radiation law [26] and Wein's law [27] shown in Eq.(1) and Eq.(2) respectively.

$$
\begin{gathered}
E=\frac{2 \pi h c^{2}}{\lambda^{5}\left(e^{\frac{h c}{\lambda k T}}\right)-1} . \\
\lambda_{\max } T=2.898 \times 10^{-3} \text { m.k. }
\end{gathered}
$$

Table 3: Properties of InAs and InSb photocells.

\begin{tabular}{lll}
\hline Specfications / Type of Photocells & InAs & InSb \\
Spectral response $(\mu \mathrm{m})$ & $1.0-3.8$ & $1.0-5.5$ \\
Temperature detection range & Min: $253.75^{\circ} \mathrm{C}$ & Min: $253.75^{\circ} \mathrm{C}$ \\
& Max: $2624.85^{\circ} \mathrm{C}$ & Max: $489.48^{\circ} \mathrm{C}$ \\
Peak sensitivity wavelength $(\mu \mathrm{m})$ & 3.0 & 5.3 \\
Specific detectivity $\mathrm{D}^{*}\left(\mathrm{~cm}^{*} \mathrm{~Hz}^{1 / 2} / \mathrm{W}\right)$ & $8.0 \times 10^{9}$ & $8.0 \times 10^{6}$ \\
Response time $(\mu \mathrm{s})$ & 1 & 0.6 \\
Operating temperature $(\mathrm{K})$ & 77 & 77 \\
\hline
\end{tabular}




\section{RESULTS AND DISCUSSION}

\section{Calibration of Pyrometer}

Correlation between the temperature of heated insert carbide and its respective temperature was tabulated in Table 4 and drawn in Figure 4. A heated insert carbide reached a peak temperature at $907.8^{\circ} \mathrm{C}$ and its corresponding InAs-InSb voltage ratio is 39.40 . The heated carbide is let cool down with minimal thermal shock until $225^{\circ} \mathrm{C}$ and at the same time its corresponding InAs-InSb voltage ratio is calibrated based on the standard set by ASTM E20.02 (2014) [27] and previous research study [6-7, 10, 28]. It was found that there is lower limit of the calibration graph. When the temperature was let cooled down as shown in Figure 3 and reached $247.216^{\circ} \mathrm{C}$, no changes in the voltage ratio was observed as shown in Table 4. This is due to the lowest spectral response of the InAs-InSb detector that can be detected is $5.5 \mu \mathrm{m}$ or $253.75^{\circ} \mathrm{C}$ and the highest spectral response is $1.0 \mu \mathrm{m}$ or $2624.85^{\circ} \mathrm{C}$. From the graph in Figure 4, a calibration Eq.(3) can be obtained from the graphical analysis software, NGraph.

$$
T\left({ }^{\circ} \mathrm{C}\right)=e^{5.258}(\operatorname{InAs} / \operatorname{InSb})^{0.419}
$$

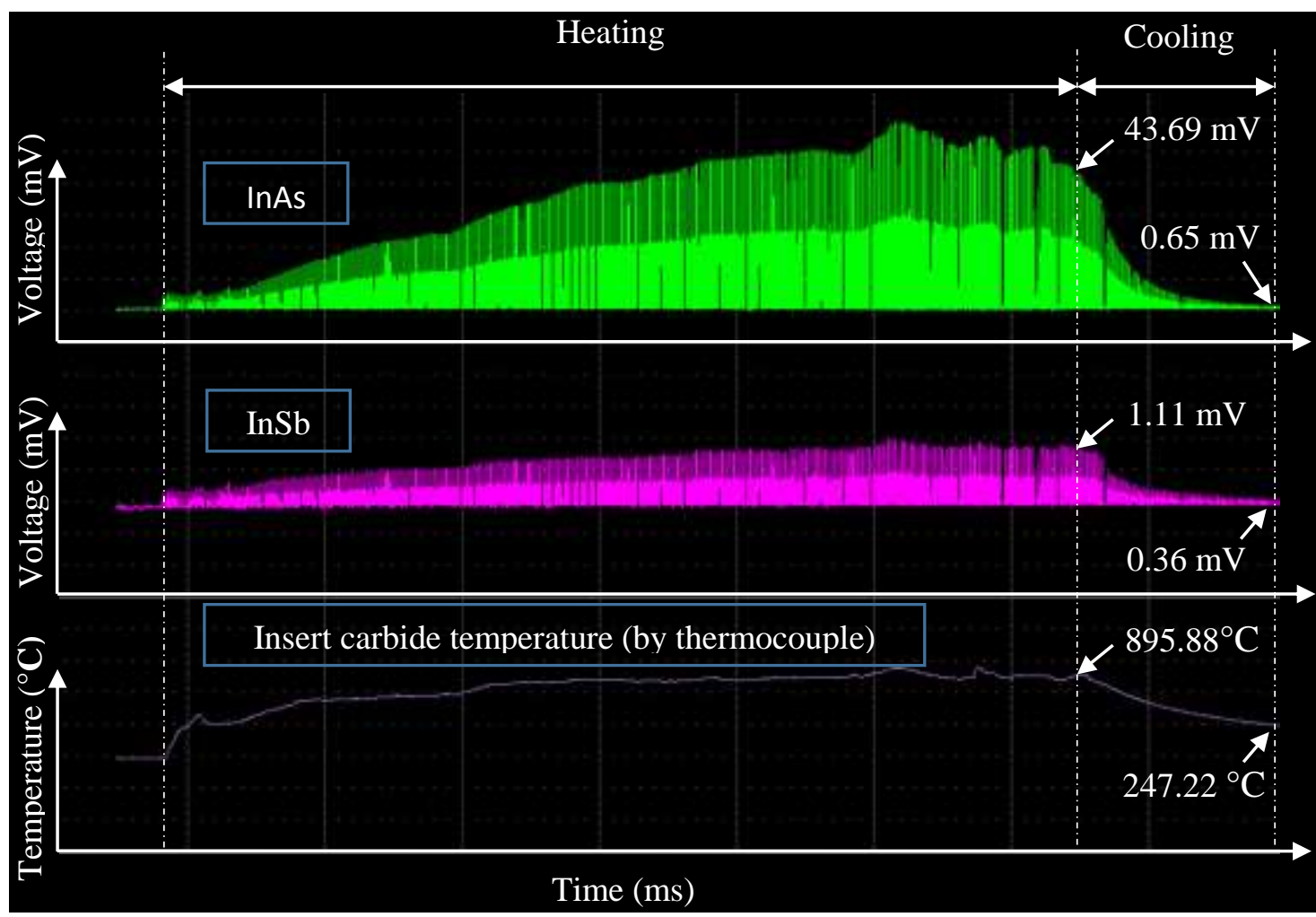

Figure 3: InAs, InSb, and temperature of insert carbide displayed by Xviewer software. 
Table 4: Calibration data of pyrometer

\begin{tabular}{l|l|l|l}
\hline \multicolumn{4}{|c}{ Calibration of Pyrometer } \\
\hline Ratio & $\begin{array}{l}\text { Tempera } \\
\text { ture }\left({ }^{\circ} \mathrm{C}\right)\end{array}$ & Ratio & $\begin{array}{l}\text { Temperat } \\
\text { ure }\left({ }^{\circ} \mathrm{C}\right)\end{array}$ \\
\hline 39.399 & 895.884 & 12.543 & 554.558 \\
\hline 37.242 & 874.999 & 11.875 & 541.986 \\
\hline 34.192 & 844.225 & 10.416 & 513.029 \\
\hline 32.902 & 830.729 & 8.334 & 467.244 \\
\hline 32.413 & 825.535 & 7.442 & 445.596 \\
\hline 31.699 & 817.856 & 7.065 & 436.004 \\
\hline 27.408 & 769.497 & 5.833 & 402.371 \\
\hline 26.384 & 757.315 & 5.189 & 383.093 \\
\hline 23.479 & 721.183 & 4.322 & 354.858 \\
\hline 23.000 & 714.993 & 3.305 & 317.126 \\
\hline 21.110 & 689.753 & 2.500 & 282.118 \\
\hline 16.842 & 627.456 & 1.824 & 247.216 \\
\hline 15.882 & 612.210 & 1.875 & 250.071 \\
\hline 13.334 & 568.956 & 1.795 & 245.554 \\
\hline
\end{tabular}

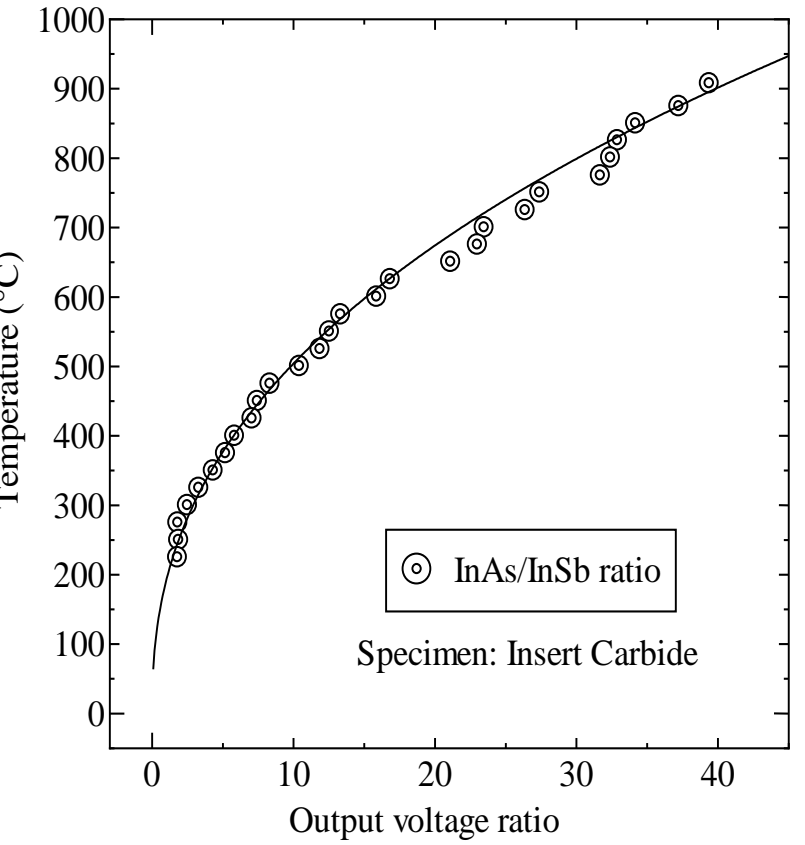

Figure 4: Graph of calibration curve

\section{Cutting experiment}

A simple cutting experiment with a cutting condition stated in Table 1 was carried out to determine the cutting edge temperature. Its signal output was recorded as shown in Figure 6. InSb was not shown as it have similar pattern with InAs. Three regions were identified based on the pulse or peak strength pattern. For this cutting experiment, Region B was chosen as an interest region to analyse cutting edge temperature. Region A shows the beginning of cutting process where InAs signal are consistently rising until point $\mathrm{A}_{1}$. This was due to the major of heat flux was preserved in workpiece [29]. During initial cutting, the radial depth of cut was not completely feed the workpiece as shown in Figure 5. Therefore, initial chip's total length is short thus, tool-chip contact length, $\mathrm{L}_{\mathrm{f}}$ is not long. Meanwhile, the dynamometer shows a fluctuating cutting force reading as the piezoelectric sensor is in premature state until point $\mathrm{A}_{1}$. Beyond point $\mathrm{A}_{2}$, cutting force begins to stabilise and steadily increasing. Cutting temperature at region B shows consistent reading as well as its cutting force. This was caused by the interaction between tool-chip interfaces have achieved stable net flow of heat energy. Region $\mathrm{C}$ resembles the post cutting process. Noted that, there are residual cutting temperature from previous cutting detected by pyrometer. Dynamometer is still giving a cutting force signal but it can be ignored as it is residual vibration signal from cutting process of Region B. 


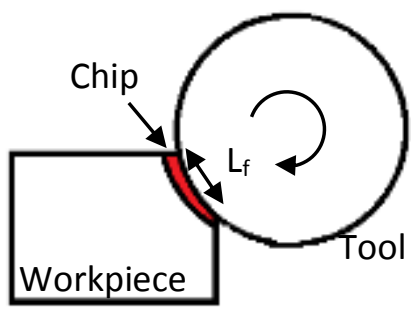

(a)

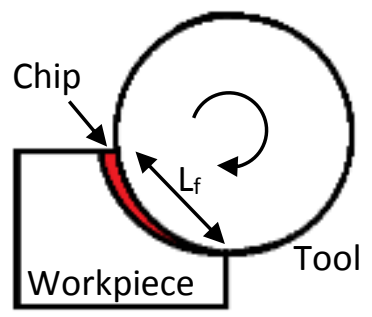

(b)

Figure 5: Top view of (a) initial cutting - Prior to point $A_{2}$; (b) mid cutting - Region $B$

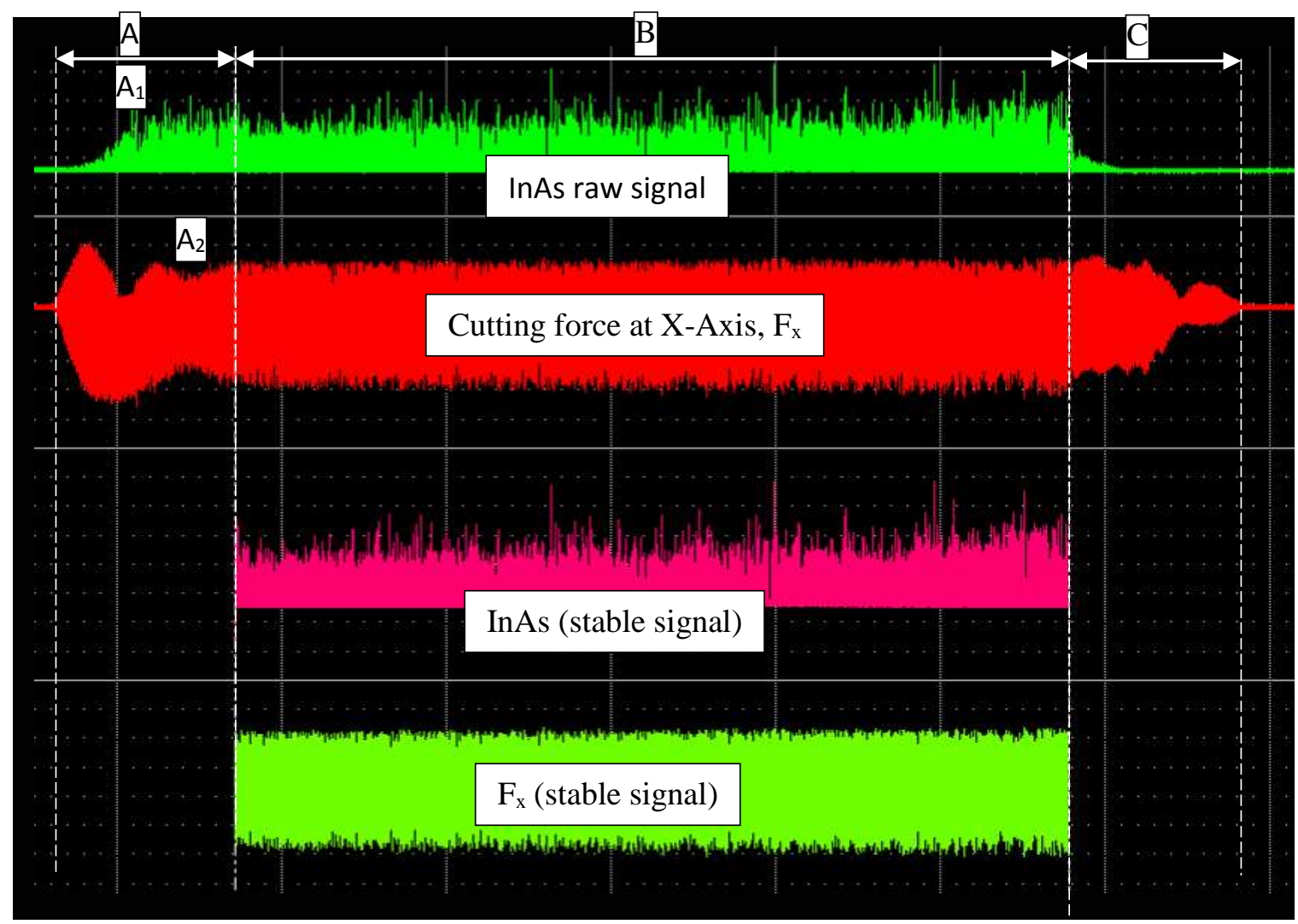

Figure 6: Recorded output signal of InAs photocell and Cutting Force (X-Axis)

\section{Characteristics of Output Waves from Cutting Experiment}

Figure 7 and Figure 8 shows the characteristic output waves of bichromatic pyrometer during cutting experiment. The original data was drawn in the upper figure while the lower figure represents a conditioned signal. Each pulse represents a heat passed through an optical fiber. The heat was emitted from the cutting edge of insert carbide. Photocells accept the infrared waves based on its respective spectral response as mentioned in Table 3. Combination of InAs and InSb photocells gave a wide range of temperature detection where both InAs and InSb were capabled to detect the temperature of the tool's cutting edge higher than $489.48^{\circ} \mathrm{C}$ effectively, while temperature lower than $489.48^{\circ} \mathrm{C}$ is effectively detected by InAs photocells. The period between each pulse is $11.7 \mathrm{~ms}$ and the pyrometer are capable to detect changes in temperature at a span of $0.01 \mathrm{~ms}$. This pyrometer have been used previously by 
[7] to detect cutting temperature for cutting speed up to 35,000 RPM. Each pulse represents one revolution of the cutting edge. By dividing a peak voltage output from InAs (Figure 7) to $\mathrm{InSb}$ (Figure 8), a voltage ratio was obtained. This voltage ratio is then converted to a temperature scale by referring to the calibration curve from Figure 4 and equation (3).

\section{Signal conditioning by Gaussian filter method and baseline correction}

InAs and InSb photocells are susceptible to low and high bandwidth noise [30-32]. Possible sources of high bandwidth noise in the factory are vibrations from milling machine, rotary equipment, electromagnetic equipment and surging electrical power outlet while source of low bandwidth noise are from unconditioned power source [33]. The UPS contains a 1:1 ratio isolation transformer and a backup battery to condition a power source [34]. A signal from InAs and InSb detector cells have been conditioned further by Gaussian filter method to reduce low and high bandwidth noise, and baseline correction as shown in lower figure in Figure 7 and Figure 8 respectively [35-37]. Reducing the low bandwidth noise and correcting the baseline can increase the accuracy of the recorded data. InSb detector cells have higher sensitivity to noise than InAs due to its specific detectivity is lower than InAs (Table 3).

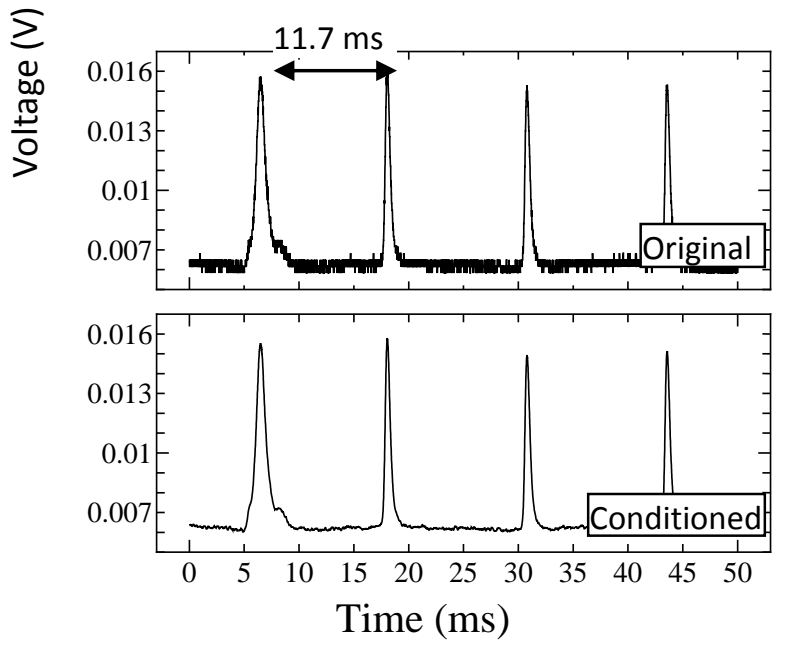

Figure 7: Output wave from InAs photocell.

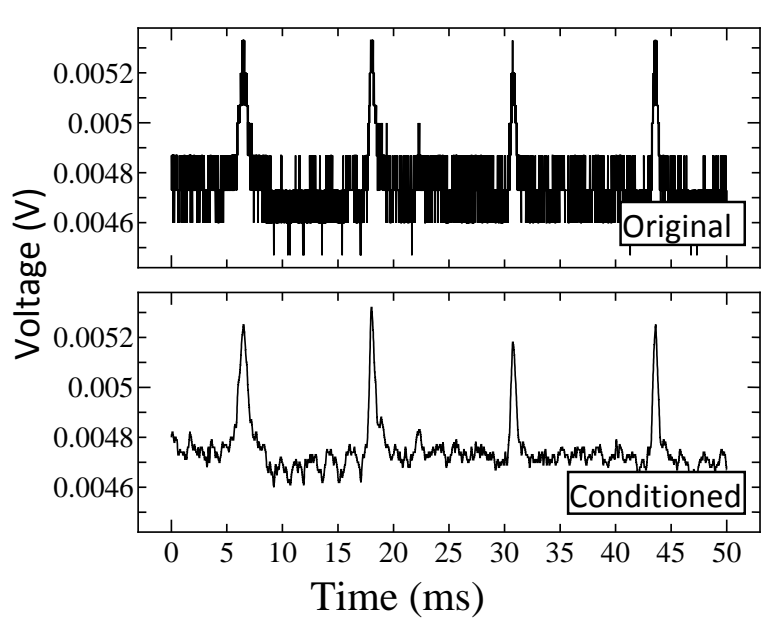

Figure 8: Output wave from InSb photocell.

\section{Presence of Baseline Error}

Existence of external signal noise during cutting experiment are unavoidable as discussed in previous section. This is due to the voltage output of the photocell are in millivolt scale. Therefore, any micro voltage changes will affect the true voltage value. Unstable current input to the photocell from the power supply have major impacts on the current output. This situation have imposed a linear and nonlinear error phenomenon of the ground voltage value of the output signal as indicated in Figure 9 and Figure 10. Deviation of ground value during cutting experiment is extremely affecting the reading of InAs and InSb voltage. The deviation is about 0.5 to $3.12 \mathrm{mV}$. This deviation is large enough to give an error in a temperature conversion ranging from $50^{\circ} \mathrm{C}$ to $200^{\circ} \mathrm{C}$. 


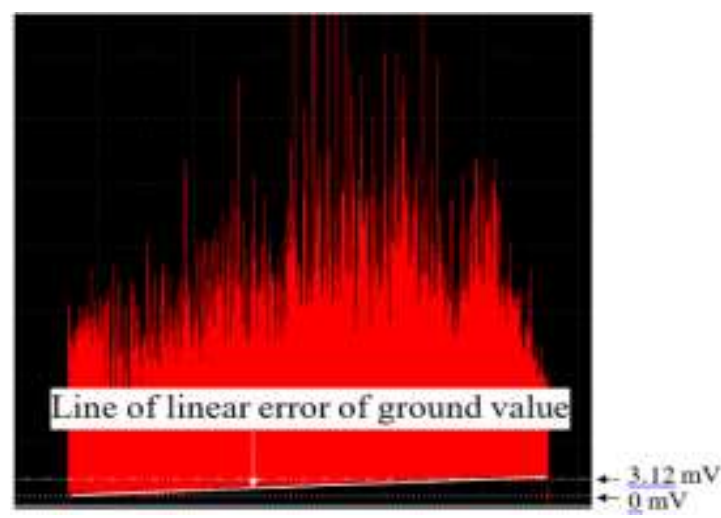

Figure 9: Linear ground value of InAs from the cutting experiment of $283 \mathrm{~m} / \mathrm{min}$

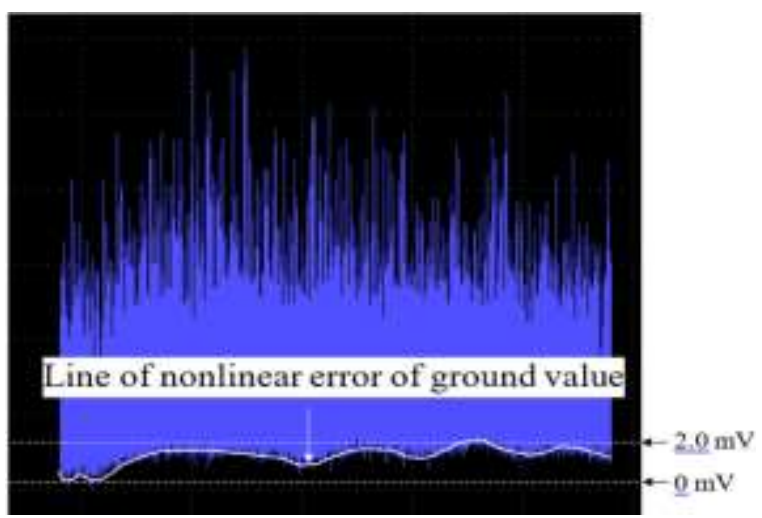

Figure 10: Nonlinear ground value of InAs from the cutting experiment of $283 \mathrm{~m} / \mathrm{min}$

\section{Detrending Baseline Error}

Those baseline error mentioned previously were corrected by using numerical programming approach with Matlab software as shown in Table 5 and Figure 11. This correction method concept was proposed by Luo et al (2013) [36]. The programming shown in Table 5 was based on the electrocardiogram (ECG) signal correction method documented by Matlab software [38]. This programming method is compatible for our cutting temperature signal because of its similar repetitive intermittent pattern. This method are also applicable for InSb sensor as well.

Table 5: Programming used in Matlab software to correct the baseline error

\begin{tabular}{|c|c|}
\hline Type & Programming sequence used \\
\hline Linear & dtInAs.LinearError = csvread('InAs from 95 WDF.csv') \\
\hline Error & dtInAs.Linear $=$ detrend(dtInAs.LinearError $)$ \\
\hline Non Linear & InAs $=$ csvread ('InAs from 96 WDF.csv') $\longleftarrow \quad$ Import data \\
\hline Error & 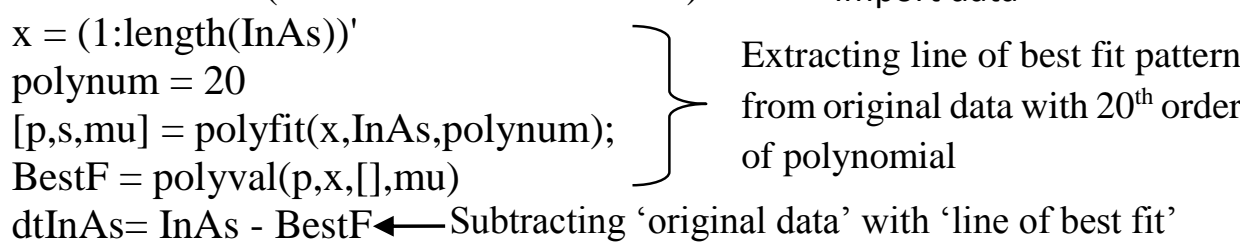 \\
\hline
\end{tabular}

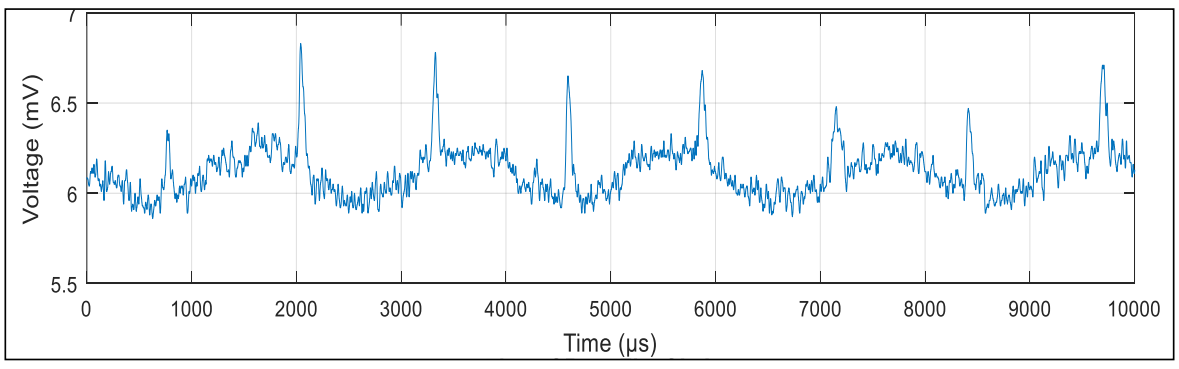


Original InAs data

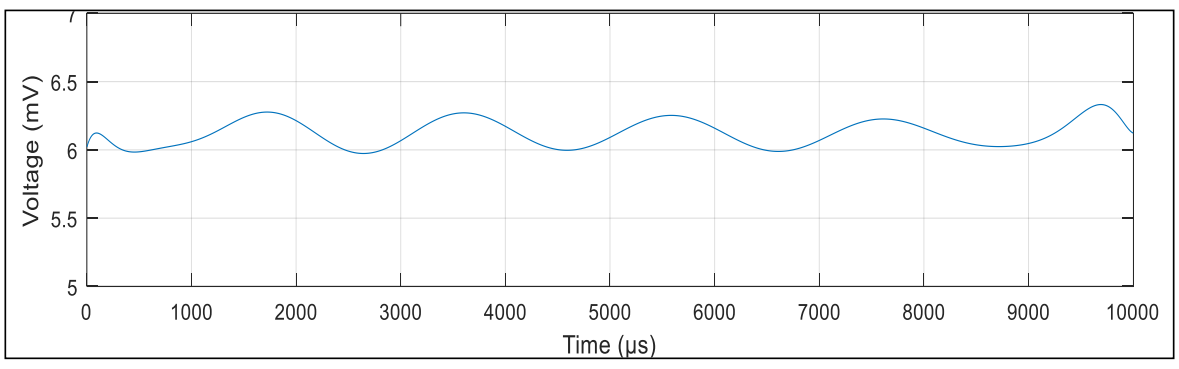

Extracting line of best fit from original data

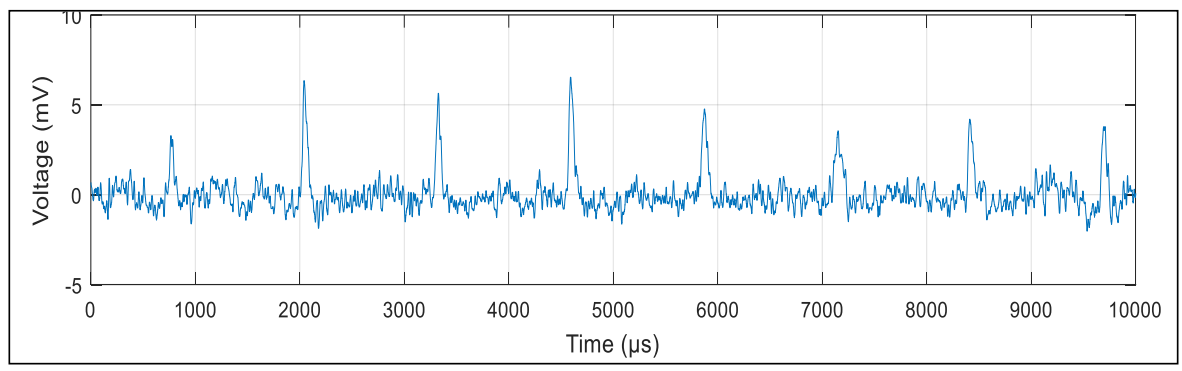

Baseline error was removed

Figure 11: Removal of baseline error viewed in Matlab software

Peak Trend Formation

Each impulse produced by InAs and InSb voltage ratio is produced by cutting edge's heat passed through in front of optical fiber's input tip. The heat is produced by work done required by cutting tool to cut the workpiece and to overcome frictional force interaction between tools, chip and workpiece [39-40]. Infrared waves is radiated from the hot surfaces of cutting edge tool. Formation of output waves is visualized in Figure 12. A peak is slowly develop when radiated cutting edge is moving in front of optical fiber. The peak trend is in sequential order with the cutting force based on its feed path angle (Figure 14). 


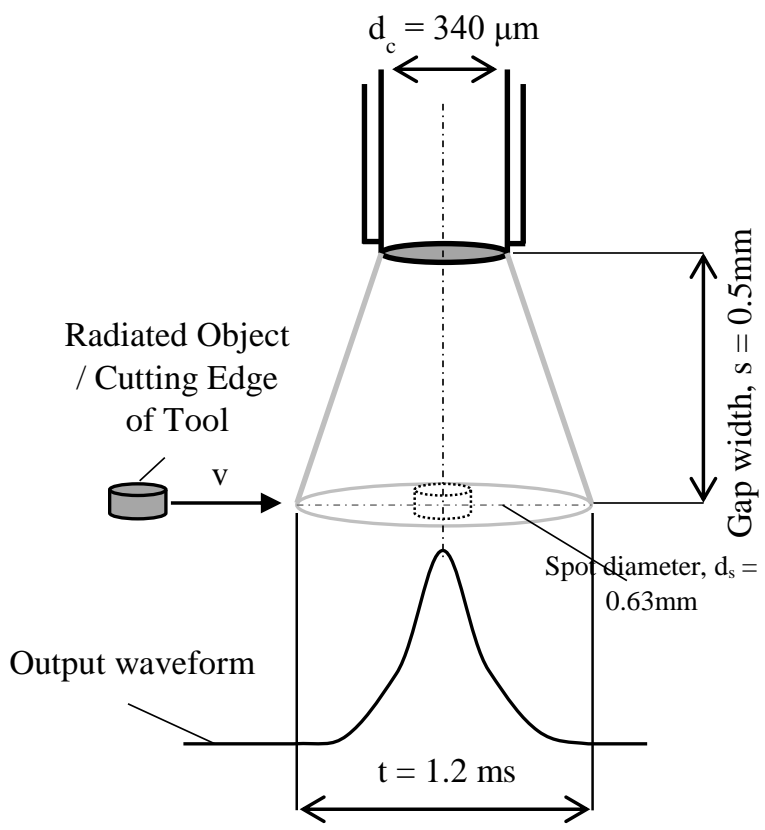

Figure 12: Formation of output waveform when cutting edge passed through optical fiber.

\section{Deceleration of Cutting Tool Detected by Pyrometer and Dynamometer}

Theoretically, the difference of position angle between dynamometer input and photocells input is by $66.4^{\circ}$ (Figure 13). By experiment, the actual difference of position angle between dynamometer input and photocells input is by $65.72^{\circ}$ (Figure 14). The differences occurred were due to the deceleration of cutting tool when the cutting edge cuts through position A to $\mathrm{B}$ as shown in Figure 13 and Figure 14 [17, 41]. Once cutting tool passed through after position $\mathrm{B}$, the cutting tool regains back to its constant angular velocity. Another possible reason is the tip of optical fiber vibrates due to the presence of cutting force from the machining process. Noted that, even though the cutting feed ends at position $\mathrm{B}$, the reading of cutting force is still exist. This is due to the residual vibration from cutting force of A to B was still detected by dynamometer [17, 43]. 

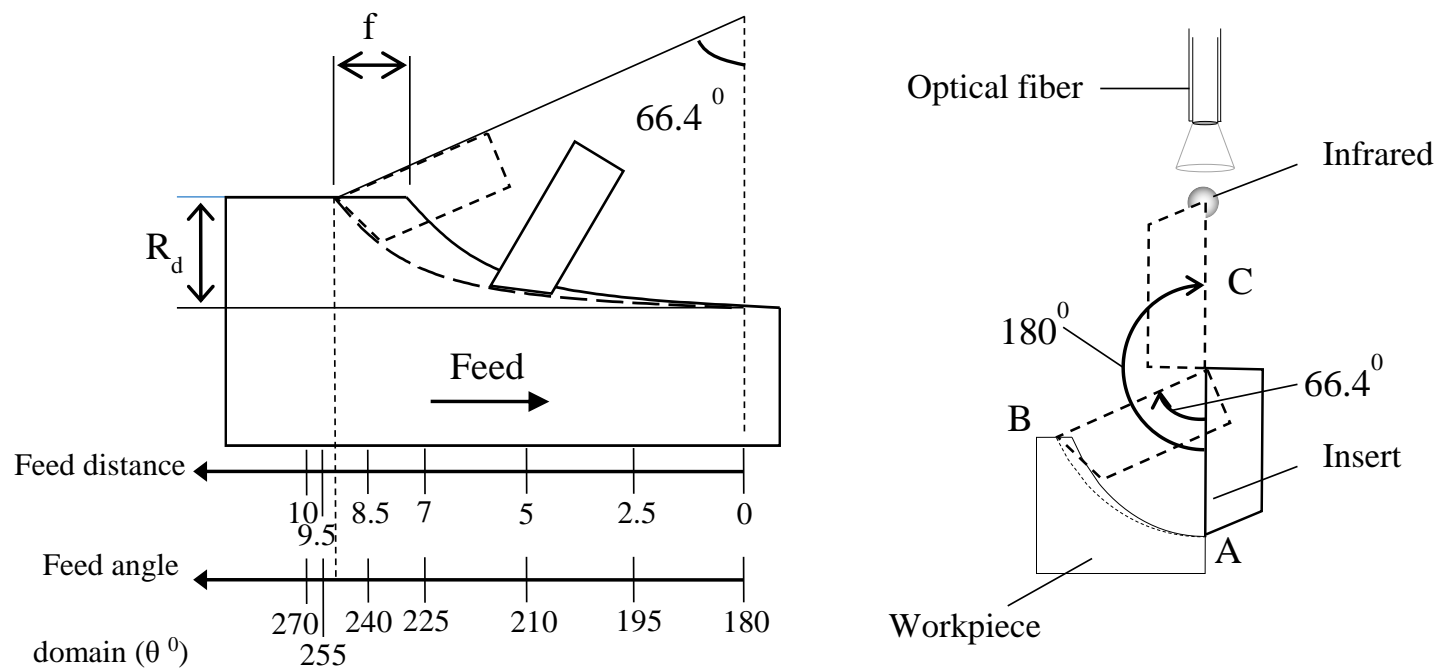

Figure 13: Theoretical position of cutting feed at cutting speed of $283 \mathrm{~m} / \mathrm{min}$ at $\mathrm{Rd}=6 \mathrm{~mm}$ and $\mathrm{Ad}=0.5 \mathrm{~mm}$.
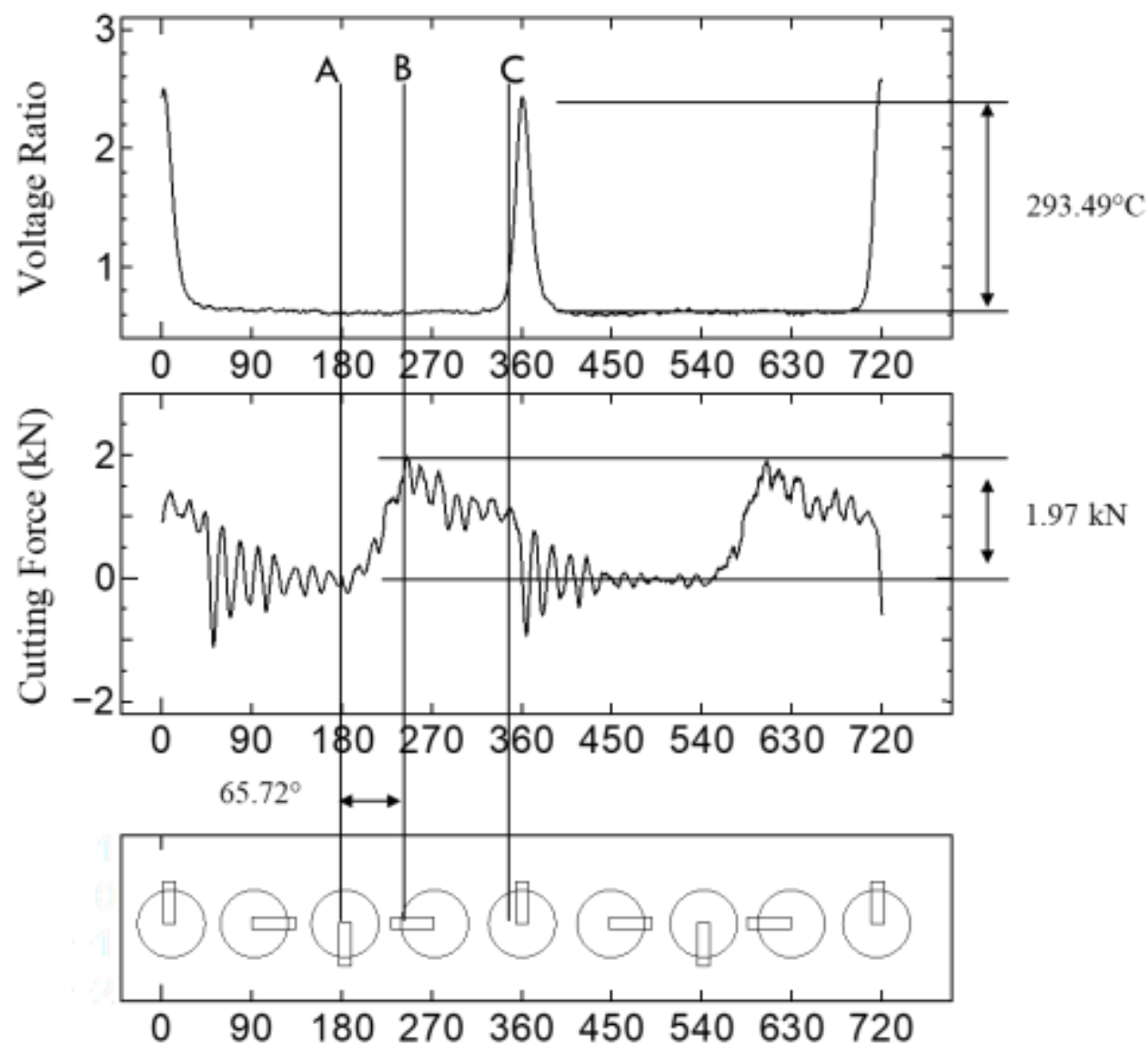

Figure 14: Actual position of cutting feed at cutting speed of $283 \mathrm{~m} / \mathrm{min}$ at $\mathrm{Rd}=6 \mathrm{~mm}$ and $\mathrm{Ad}=0.5 \mathrm{~mm}$. 


\section{CONCLUSIONS}

In this paper, a novel method of development infrared radiation measurement for end mill tool is developed. The main results are analyzed as follows.

1. Experimental method of using bichromatic pyrometer with an optical fiber to measure cutting edge temperature was developed, in which infrared radiation technique is capable to detect high response rate of cutting edge temperature. The pyrometer are capable to detects temperature changes at a span of $0.01 \mathrm{~ms}$. This pyrometer can be used on high speed machining up to 35,000 RPM.

2. Three regions of signal were observed from photocells and dynamometer which are initial cutting, mid cutting and post cutting. Each region shows different pattern of data. A signal during mid cutting region was chosen as an interest.

3. The noises and error are minimized with the introduction of UPS battery, Gaussian filter method and baseline correction.

4. At a cutting speed of $283 \mathrm{~m} / \mathrm{min}$ in up milling direction, the cutting edge temperature is approximately $293.49^{\circ} \mathrm{C}$ and cutting force is $1.97 \mathrm{kN}$

5. The deceleration of cutting tool's rotation was found. The differences of angle between theoretical and actual position of cutting tool is $0.68^{\circ}$.

6. This pyrometer can be used to profile the cutting edge temperature of both conductive and nonconductive cutting tool in machining industry as well as for cutting performance analysis such as study of tool life and tool wear.

The developed cutting edge temperature measurement by using infrared radiation technique can be applied on the other material machining application such as abrasive grinding, braking pad, micro drilling, and micro turning. Since, previous researcher converts the temperature reading from the pyrometer signal manually, thus authors also would plan to develop a programming for direct temperature conversion of pyrometer signal which can detects the peak value of cutting temperature automatically in the future.

\section{ACKNOWLEDGEMENTS}

The authors would like to express their gratitude to the project main sponsors, UNIMAS Exploratory Research Grant Scheme: ERGS/TK01(01)/1007/2013 (04) for giving the fund assistance to equip the laboratory with appropriate tools and devices to conduct this project. 


\section{REFERENCES}

[1] Hou J, Zhou W, Duan H, Yang G, Xu H, Zhao N. Influence of cutting speed on cutting force, flank temperature, and tool wear in end milling of Ti-6Al-4V alloy. International Journal of Advanced Manufacturing Technology 2014; 70(9-12): $1835-1845$.

[2] Abukhshim NA, Mativenga PT, Sheikh MA. Heat generation and temperature prediction in metal cutting: A review and implications for high speed machining. International Journal of Machine Tools and Manufacture 2006; 46(7-8): 782-800.

[3] KaruppannaRaja PG, Rajkumar M, Senthil Kumaran S. A study on backing block arrangement of dissimilar metal joining process of seamless ferritic and austenitic alloy by using an external tool. Journal of Alloys and Compounds 2016; 687(1): 773785.

[4] Venkatesan K. The study on force, surface integrity, tool life and chip on laser assisted machining of inconel 718 using Nd:YAG laser source. Journal of Advanced Research 2017; 8(4): 407-423.

[5] Sato M, Tamura N, Tanaka H. Temperature Variation in the Cutting Tool in End Milling. Journal of Manufacturing Science and Engineering 2011; 133(2): 21005.

[6] Ueda T, Hosokawa A, Oda K, Yamada K. Temperature on Flank Face of Cutting Tool in High Speed Milling. CIRP Annals - Manufacturing Technology 2001; 50(1): $37-40$.

[7] Kiprawi MA, Yassin A, Syed Shazali ST, Islam MS, Mohd Said MA. Study of Cutting Edge Temperature and Cutting Force of End Mill Tool in High Speed Machining. MATEC Web Conference 2017; 87(1): 02030.

[8] Teo CY, Yassin A. Cutting Temperature and Tool Wear Assessment of Turning Process with Minimal Quantity Lubrication. Applied Mechanics and Materials 2015; 761(1): 313-317.

[9] Yassin A, Ueda T, Furumoto T, Hosokawa A, Tanaka R, Abe S. Experimental investigation on cutting mechanism of laser sintered material using small ball end mill. Journal of Materials Processing Technology 2009; 209(15-16): 5680-5689.

[10] Jamaludin, AS, Yassin A. Analysis of laser sintered materials using finite element method. Sains Malaysiana 2013; 42(12): 1727-1733.

[11] Jamaludin, AS, Yassin A, Osman MS. Study on Ball End Milling Process Using Two Dimensional Finite Element Method. Jurnal Mekanikal 2012; 34(1): 1-15.

[12] Zhao GY, Liu ZY, He Y, Cao HJ, Guo YB. Energy consumption in machining: Classification, prediction, and reduction strategy. Energy 2017; 133(1): 142-157.

[13] Liew PJ, Shaaroni A, Sidik NAC, Yan J. An overview of current status of cutting fluids and cooling techniques of turning hard steel. International Journal of Heat and Mass Transfer 2017; 144(1): 380-394.

[14] Sasahara H, Satake K, Takahashi W, Goto M, Yamamoto H. The effect of oil mist supply on cutting point temperature and tool wear in driven rotary cutting. Precision Engineering 2017; 48(1): 158-163.

[15] Yassin A, Teo CY. Effect of Pressure and Nozzle Angle of Minimal Quantity Lubrication on Cutting Temperature and Tool Wear in Turning. Applied Mechanics and Materials 2015; 695(1): 676-679. 
[16] Di C, Dinghua Z, Baohai W, Ming L. An Investigation of Temperature and Heat Partition on Tool-chip Interface in Milling of Difficult-to-Machine Materials Procedia CIRP 2017; 58(1): 49-54.

[17] Ma Y, Feng P, Zhang J, Wu Z, Yu D. Prediction of surface residual stress after end milling based on cutting force and temperature. Journal of Materials Processing Technology 2016; 235(1): 41-48.

[18] Ma Y, Yu D, Feng P, Wu Z, Zhang J. Finite element method study on the influence of initial stress on machining process. Advances in Mechanical Engineering 2015; 7(3): $1-10$.

[19] Di C, Dinghua Z, Baohai W, Ming L. An investigation of tool temperature in end milling considering the flank wear effect. International Journal of Mechanical Sciences 2017; 131-132(1): 613-624.

[20] Furumoto T, Ueda T, Kobayashi N, Yassin A, Hosokawa A, Abe S. Study on laser consolidation of metal powder with Yb: fiber laser-Evaluation of line consolidation structure. Journal of Materials Processing Technology 2009; 209(18-19): 59735980.

[21］Ueda T. 熱輻射線による加工温度計測技術の開発 [Development of Infrared Radiation Pyrometer with Optical Fiber]. Journal of the Japan Society for Precision Engineering 2015; 81(8): 735-739.

[22] Usamentiaga R, Venegas P, Guerediaga J, Vega L, Molleda J, Bulnes F, Infrared Thermography for Temperature Measurement and Non-Destructive Testing. Sensors 2014; 14(7): 12305-12348.

[23] Ueda T, Sato M, Sugita T. Measurement of Tool-Workpiece Interface Temperature by Two-Color Pyrometer. Journal of the Japan Society for Precision Engineering 1995; 61(10): 1448-1452.

[24] Tapetado A, Diaz-Alvarez J, Miguelez MH, Vazquez C. Two-color pyrometer for process temperature measurement during machining. Journal of Lightwave Technology 2016; 34(4): 1380-1386.

[25] Grzesik W. Advanced Machining Processes of Metallic Materials. $2^{\text {nd }}$ ed. Netherland: Elsevier; 2017.

[26] Planck M, Phys A. On the Law of the Energy Distribution in the Normal Spectrum 1901; 4(553): 1-11.

[27] Norton JD. Atoms, entropy, quanta: Einstein's miraculous argument of 1905. Studies in History and Philosophy of Science Part B: Studies in History and Philosophy of Modern Physics. Elsevier 2006; 37(1): 71-100.

[28] ASTM E20.02. ASTM E2847-14: Standard Test Method for Calibration and Accuracy Verification of Wideband Infrared Thermometers. West Conshohocken: Annual Book of ASTM Standards; 2014.

[29] Jiang F, Liu Z, Yang F, Zhong Z, Sun S. Investigations on tool temperature with heat conduction and heat convection in high-speed slot milling of Ti6Al4V. The International Journal of Advanced Manufacturing Technology 2018; 96(5-8): 18471858.

[30] Karatsori TA, Pastorek M, Theodorou CG, Fadjie A, Wichmann N, Desplanque L, Ghibaudo G. Static and low frequency noise characterization of ultra-thin body InAs MOSFETs. Solid-State Electronics 2017; 143(1): 56-61. 
[31] Moschetti G, Lefebvre E, Fagerlind M, Nilsson PÅ, Desplanque L, Wallart X, Grahn J. DC, RF and noise performance of InAs/AlSb HEMTs with in situ CVD SiNx-film for early-protection against oxidation. Solid-State Electronics 2013; 87(1): 85-89.

[32] Wörl A, Rehm R, Walther M. Excess noise in InAs/GaSb type-II superlattice pinphotodiodes. Infrared Physics and Technology 2013; 61(1): 5-8.

[33] Wieder HH. Chapter 5: Devices and applications. Intermetallic Semiconducting Films 1970; 248a(249-288):231-248

[34] de Silva CW. Sensors and Actuators: Engineering System Instrumentation. $2^{\text {nd }}$ Ed. Boca Raton: CRC Press, 2015, p 322-340.

[35] Cuomo S, De Pietro G, Farina R, Galletti A, Sannino G. A novel O(n) numerical scheme for ECG signal denoising. Procedia Computer Science 2015; 51(1): 775-784.

[36] Luo Y, Hargraves RH, Belle A, Bai O, Qi X, Ward K, Najarian K. A hierarchical method for removal of baseline drift from biomedical signals: Application in ECG analysis. The Scientific World Journal 2013; 2013(1): 1-10.

[37] Nazarpour K, Al-Timemy AH, Bugmann G, Jackson A. A note on the probability distribution function of the surface electromyogram signal. Brain Research Bulletin 2013; 90(1): 88-91.

[38] Mathworks. Remove Trends from Data. Retrieved from https://www.mathworks.com/help/pdf_doc/signal/signal_tb.pdf; 1 April, 2018.

[39] Putz M, Schmidt G, Semmler U, Oppermann C, Bräunig M, Karagüzel U. Modeling of Heat Fluxes during Machining and Their Effects on Thermal Deformation of the Cutting Tool. Procedia CIRP 2016; 46(1): 611-614.

[40] Schindler S, Zimmermann M, Aurich JC, Steinmann P. Modeling deformations of the workpiece and removal of material when turning. Procedia CIRP 2013; 8(1): 3944.

[41] Jomaa W, Songmene V, Bocher P. Surface finish and residual stresses induced by orthogonal dry machining of AA7075-T651. Materials 2014; 7(3): 1603-1624.

[42] Furutani K, Sakata A. Reduction of Residual Vibration of Piezoelectric Actuator Driven by Series of Current Pulses. IEEJ Transactions on Sensors and Micromachines 2017; 137(1): 8-14.

[43] Rizal M, Ghani JA, Husni, Husaini. Design and construction of a strain gauge-based dynamometer for a 3-axis cutting force measurement in turning process. Journal of Mechanical Engineering and Sciences (JMES) 2018; 12(4): 4072-4087. 